\title{
Wave interaction with a vertical wall: SPH numerical and experimental modeling
}

\author{
E. Didier*, D.R.C.B. Neves, R. Martins, M.G. Neves \\ National Laboratory for Civil Engineering, Av. do Brasil 101, 1700-066 Lisbon, Portugal
}

\section{A R T I C L E I N F O}

\section{Article history:}

Received 31 January 2013

Accepted 22 June 2014

\section{Keywords:}

Smoothed particle hydrodynamics (SPH)

Wave-structure interaction

Coastal engineering

Impact loads

Physical modeling

\begin{abstract}
A B S T R A C T
Prediction of wave forces on caisson-type breakwaters is challenging, especially in the case of impact loads that strongly depend on wave reflection, and wave breaking which affects the wave characteristics near the structure. In recent years, numerical models have been further developed and their use is becoming increasingly attractive, such as the Smoothed Particle Hydrodynamics (SPH) numerical models which enable the simulation of complex free surface flows. The SPH numerical model developed at the National Laboratory for Civil Engineering (LNEC) is validated by comparing the numerical results of the wave interaction with a vertical wall using data obtained from physical modeling tests carried out in one of the LNEC's flumes. The numerical results presented a good agreement with the physical model tests. The free surface level was well estimated, with a concordance index between numerical results and experimental data of about $90.5-99.1 \%$, presenting an average value of 95.5\%. Pressure at the vertical wall shows high intensity and short duration impact loads, and presented a concordance index between numerical results and experimental data about $68.8-94.4 \%$, with an average value about $86.2 \%$. Considering the complex phenomena involved, which is highly difficult to be accurately modeled, numerically and experimentally, a good agreement between physical tests and numerical results was accomplished.
\end{abstract}

(c) 2014 Elsevier Ltd. All rights reserved.

\section{Introduction}

The prediction of wave forces on caisson-type breakwaters is very difficult, especially in the case of impact loads that strongly depend on wave reflection and wave breaking, which affect the wave characteristics near the structure (PROVERBS, 1999). The impact loads present high intensities for short periods, often closer to $1 / 100$ times a period, and are strongly influenced by the air effects while "pulsating" or while the "quasi-static" loads occur with durations around 0.2-0.5 times a wave period (Cuomo et al., 2010).

The forces on a vertical wall of a breakwater are usually predicted by using a semi-empirical formula or by physical modeling. However, numerical modeling is becoming an attractive tool for calculating forces on coastal structures. Nevertheless, only few numerical models allow simulating the complex phenomena of wave breaking and overtopping, and consequently forces at vertical structures. Some examples of model applications to simulate the pressure at vertical structures are the 2D RANS model COBRAS-UC (Lara et al., 2008, Guanche et al., 2009) or, more

\footnotetext{
* Corresponding author. Tel.: +351 21844 3904; fax: +351 218443011.

E-mail addresses: edidier@lnec.pt (D. E.), dneves@lnec.pt (N. D.R.C.B.), ricardomartins3@gmail.com (M. R.), gneves@lnec.pt (N. M.G.).
}

recently, a 3D RANS model application of OPENFOAM@ (Higuera et al., 2014) based on Volume of Fluid (VoF) approach, or a 2D RANS Particle Finite Element Method (PFEM) (Oñate et al., 2004). Models, based on a Lagrangian method, such as the Smoothed Particle Hydrodynamics (SPH), have emerged recently and are a very interesting option for modeling complex free surface flows. The SPH method is based on the Lagrangian formulation of the Navier-Stokes equations and on a completely mesh-free technique. Based on this technique, different models and several numerical implementations have been developed (Crespo, 2008; Gotoh et al., 2001; Shao, 2010).

The weakly-compressible SPH (WCSPH) model used at the National Laboratory for Civil Engineering (LNEC) is based on the original SPHysics model (Gómez-Gesteira et al., 2008, 2012; SPHysics code v1.4, 2009) inspired by the formulation of Monaghan (1992), and has been especially improved for modeling waves interacting with coastal structures (Didier and Neves, 2008, 2009a, 2009b, 2010a, 2010b, 2012; Didier et al., 2011, 2013; Neves et al., 2012).

This paper presents the validation of the weakly-compressible SPH numerical model for the study of the wave interaction with a vertical wall. In order to accomplish this goal, a set of physical model tests were performed at LNEC in a wave flume with the 
experimental set-up and boundary conditions identical to the numerical model: the flume dimensions and the piston-type wave-maker movement are the same for both numerical and physical model. The accuracy of the numerical model was assessed, particularly regarding two phenomena: wave propagation, and wave impacts on the vertical wall.

\section{SPH numerical model}

The Smoothed Particle Hydrodinamics (SPH) numerical methods were initially applied to astrophysics by Gingold and Monaghan (1977) and Lucy (1977) and later to hydrodynamics by Monaghan $(1992,1994)$. The SPH method is a completely meshfree technique, enabling the modeling of the fluid particles trajectories accordingly to the Navier-Stokes equations written on the SPH formalism, based on the theory of interpolation integrals which use interpolation kernels. The Lagrangian approach of the SPH methods consists in following the fluid particles in a determined time interval in order to obtain its trajectories, velocities and pressures as a function of the initial position and time.

\subsection{Principle of the SPH method}

The fundamental principle of the SPH methods is to approximate a scalar, a function or a tensor using the theory of the interpolation integrals. The integral of an interpolation function $f(r)$ is given by the following equation:

$f(r)=\int f\left(r^{\prime}\right) W\left(r-r^{\prime}, h\right) d r^{\prime}$

where $r$ is the vector particle position, $W$ is the weighting function, called kernel, $h$ is the smoothing length. The kernel allows determining the interaction among neighboring particles included in their influence domain. This domain is a compact support within a circular region determined by a radius of $2 h$, controlled by the smoothing length $h$, defined as $h=0.92 * 2^{0.5} d_{0}$, with $d_{0}$ the initial particle spacing. The kernel is an analytic function which can be differentiated without requiring any spatial mesh.

Numerically, the function $f(r)$ is only known at the particles, and the interpolation integrals are approximated by the sum of the contribution of each particle included in their influence domain. The function is written as an approximation of the function $f$ at a particle $a$ at the position $r_{a}$, and is given by the following equation:

$f\left(r_{a}\right) \approx \sum_{b} m_{b} \frac{f_{b}}{\rho_{b}} W_{a b}$

where $f_{b}$ is the value of the function $f$ associated with the particle $b$ at $r_{b}, W_{a b}=W\left(r_{a}-r_{b}, h\right)$ is the value of the kernel at $\left(r_{a}-r_{b}\right), m_{b}$ and $\rho_{b}$ are the mass and the density of the particle $b$, respectively.

For numerical simulation of wave propagation, the quadratic kernel (Johnson et al., 1996; Dalrymple and Rogers, 2006) is used to determine the interaction between the particles. This kernel is defined by the analytic function:

$W(q, h)=\frac{3}{2 \pi h^{2}}\left(\frac{q^{2}}{4}-q+1\right)$

where $q=\left(r_{a}-r_{b}\right) / h$ and $0 \leq q \leq 2$. This kernel has the particularity of not having an inflection point in its first and second derivative in the range of the function definition.

\subsection{Set of equations in Lagrangian form}

The 2D momentum conservation equation and the conservation law, in Lagrangian form, for a viscous fluid are written as follow:

$\frac{d v}{d t}=-\frac{1}{\rho} \nabla P+\Pi+g$

$\frac{1}{\rho} \frac{d \rho}{d t}=-\operatorname{div}(v)$

where $t$ refers to the time, $v$ the velocity, $P$ the pressure, $\rho$ the fluid density, $\Pi$ the viscous terms and $g=(0,-9.81) \mathrm{m} / \mathrm{s}^{2}$ the gravitational acceleration.

The standard SPH formulation (Monaghan, 1994), in which the fluid is considered weakly-compressible, is used and the pressure is calculated by an equation of state (Batchelor, 1974) through the fluid density

$P=B\left[\left(\frac{\rho}{\rho_{0}}\right)^{\gamma}-1\right]$ with $B=\frac{c_{0}^{2} \rho_{0}}{\gamma}$

with $\gamma=7, \rho_{0}$ is the reference density and $c_{0}$ the speed of sound at the reference density.

The particle trajectories are obtained from the following relationship:

$\frac{d r}{d t}=v$

where $r$ is the particle position. Classically, the XSPH method (Monaghan, 1989) allows the movement of the particles with a velocity similar to the average of their neighborhood. However, the $\mathrm{XSPH}$ method can introduce some undesirable numerical artificial viscosity and numerical instabilities during the wave propagation, also some particles aquire enough velocity to cross the solid boundaries (Didier and Neves, 2009b). Thus the XSPH correction is not used in SPHyCE.

\subsection{SPH numerical model}

The SPH numerical model used at LNEC is based on the opensource code SPHysics (Gómez-Gesteira et al. 2008, 2012), version 1.4 (Crespo, 2008; SPHysics code v1.4, 2009), inspired by the SPH standard formulation of Monaghan (1994). The fluid in the standard SPH formalism is treated as weakly-compressible, allowing the direct pressure calculation through a state equation (Batchelor, 1974), that relates the fluid pressure with the density. The LNEC's SPH numerical model is specifically improved for coastal engineering problems, complex free surface flows and wave interacting with impermeable and porous coastal structures.

In the SPH equations, the discrete equation of the momentum conservation is given by the following equation:

$\frac{D v_{a}}{D t}=\sum_{b} m_{b}\left(\frac{P_{a}}{\rho_{a}^{2}}+\frac{P_{b}}{\rho_{b}^{2}}+\Pi_{a b}\right) \nabla_{a} W_{a b}+g$

where $v_{a}, P_{a}$ and $\rho_{a}$ are the velocity, pressure and density of a particle $a$, respectively, $P_{b}, \rho_{b}$ and $m_{b}$ are the pressure, density and mass of a particle $b$, respectively, included in the influence region of the kernel, $W_{a b}$ is the kernel and $\Pi_{a b}$ the viscosity term. Finally, $\nabla_{a} W_{a b}$ is the kernel gradient.

The turbulence model sub-particle scale (SPS) (Gotoh et al. 2001 ) is used since it includes not only a viscosity model but also the turbulence effect through a model derived from the LES-type models (Large Eddy Simulation). The artificial viscosity model (Monaghan, 1992), with two empirical parameters that should be calibrated, is frequently used to stabilize the numerical process but introduces a numerical diffusion that might affect significantly the wave amplitude (Didier and Neves, 2009b). 
The mass conservation equation in the discrete SPH formalism is given by the following equation:

$\frac{D \rho_{a}}{D t}=\sum_{b} m_{b}\left(u_{a}-u_{b}\right) \nabla_{a} W_{a b}$

The particles move according to the following equation:

$\frac{D r_{a}}{D t}=u_{a}$

The pressure is obtained by the equation of state, given by Eq. (6).

For numerical reasons, the sound velocity $c_{0}$ must be high enough to reduce fluctuations due to density and low enough to allow the model to run with a reasonable calculation time step. Therefore, it is usually considered, for the calculations, a sound velocity significantly lower than its classic value (Monaghan, 1994; Gomez-Gesteira et al., 2012).

The flow kinematics of the SPH models is generally realistic. However, a problem inherent to the weakly-compressible SPH (WCSPH) formulation, based on the formulation of Monaghan (1994), is that the particle pressure might exhibit large oscillations. Gómez-Gesteira et al. (2010) shows that filtering density (i.e. renormalization of particle density) allows to obtain a pressure field without oscillations and a good representation of a dambreak flow. However, filtering density influence seems to be more complex for wave propagation. Hughes and Graham (2010) compared incompressible SPH (ISPH) and WCSPH models, with and without filtering density, for waves impacting on a vertical wall. Both methods have shown to be able of simulating the pressure on the vertical wall due to the wave impacts. The predictions for the wave impacts have shown to be in agreement, qualitatively and quantitatively, with the available experimental data. Results from the WCSPH appear to be significantly smoother than those from ISPH. This is particularly the case for the free surface deformation and especially for the wave breaking. Preliminary studies (Didier et al., 2011, 2013; Martins, 2012) comparing numerical and experimental results for wave impact on a vertical breakwater showed that the conventionally used density filter stabilizes the pressure field but causes a numerical diffusion on wave propagation and a consequent reduction on wave height that is not observed in the experimental results. On the other hand, without the density filter, pressure oscillations appear and forces on structures are more difficult to be calculated. With these results, a partial filtering density technique, i.e. renormalization applied only for particles near the structure, was developed allowing to simultaneously propagate waves without diffusion and to model accurately the pressure field near the structure.

The pressure instabilities can be resolved by correcting the kernel function, recalculating the value of the particle density. The application of the density renormalization is performed every 30 iterations of time (classical value) applying the Shepard filter (Colagrossi and Landrini, 2003). The new density value of a given particle is calculated by the following equation:

$\bar{\rho}_{a}=\sum_{b} m_{b} \tilde{W}_{a b}$

$\tilde{W}_{a b}=\frac{W_{a b}}{\sum_{b} W_{a b} \frac{m_{b}}{\rho_{b}}}$

In the LNEC's SPH model, the time integration is performed using the predictor-corrector algorithm (Monaghan, 1989). The time step is automatically controlled accordingly to the CFL conditions proposed by Monaghan and Kos (1999). The particle velocity is calculated using the discrete equation of the momentum conservation, Eq. (8), the density is set by the discrete form of the continuity equation, Eq. (9), and the position of the particles is
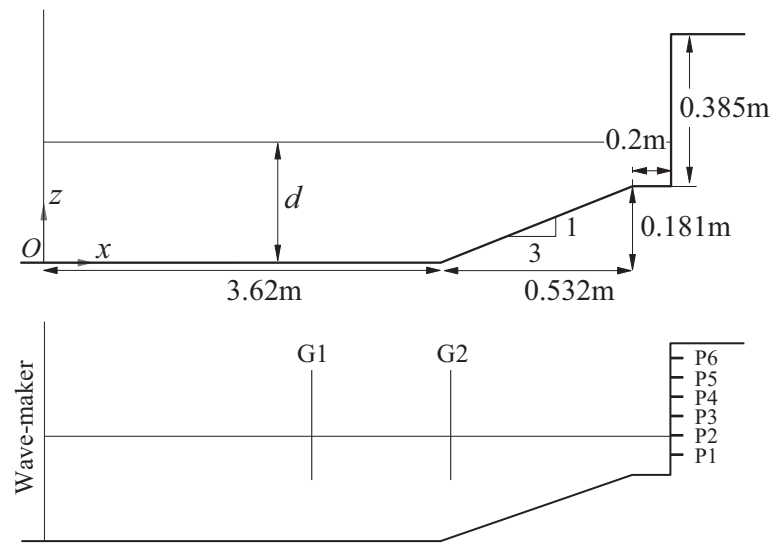

Fig. 1. Schematic representation of the wave flume and the structure and its dimensions.

calculated by Eq. (10). The pressure is calculated from the density using the Tait equation, Eq. (6).

Detail of numerical implementation is available in GómezGesteira et al. (2008, 2012), SPHysics code v1.4 (2009) and Didier and Neves (2009b, 2012), Didier et al. (2013).

\subsection{Boundary and initial conditions}

The boundary conditions are not displayed directly in the SPH formalism. In the present model the repulsive boundary condition, developed by Monaghan and Kos (1999) and corrected by Rogers and Dalrymple (2008), that imposes a repulsive force from the solid particles of the boundary to the fluid particles, is used and allows preventing the water particles to cross the solid boundary.

Initially, the water particles are placed in the flume using a regular Cartesian distribution, i.e. particles are regularly distributed, with the spacing between particles defined by $d_{o}$. This is a condition of the SPH method when the smoothing length of the kernel is constant. The distribution of the solid particles at boundaries follows the one adopted for the fluid particles, namely the distance between the particles is equal to $d_{o}$ independently of the direction of the boundaries. The velocity field is zero and the pressure is hydrostatic. The particle density is equal to the water density, $1000 \mathrm{~kg} / \mathrm{m}^{3}$.

Regular incident waves were generated using a piston-type wave-maker, with the same motion as in the experimental tests, by moving the solid particles of left boundary of the SPH numerical domain (Crespo et al., 2008).

\section{Physical modeling of wave impact on a vertical wall}

Within the aim of validating the SPH numerical model, physical tests of waves interacting with a vertical breakwater were performed in one of the LNEC's flume with $49.4 \mathrm{~m}$ length, $1.6 \mathrm{~m}$ wide and $1.2 \mathrm{~m}$ height. The flume is equipped with a piston-type wavemaker and is able to generate both regular and irregular waves.

The physical model set-up was determined in such a way that was feasible the exact replication in the numerical model, taking into account the characteristics of the numerical model, and to ensure that conditions for numerical and experimental models were identical.

The coastal structure consists on an impermeable vertical breakwater composed by a $0.181 \mathrm{~m}$ height berm with a $1: 3$ slope, and a $0.03 \mathrm{~m}$ thickness acrylic vertical wall. The vertical wall was reinforced by vertical supports on its rear part to ensure rigidity of the structure, and was located $0.2 \mathrm{~m}$ from the top of the slope, as it 
is shown in Fig. 1. The crest freeboard is $0.385 \mathrm{~m}$ above the berm. The horizontal bottom between the piston-type wave-maker and the beginning of the $1: 3$ slope was $3.62 \mathrm{~m}$ length.

The case analyzed in the present paper is an incident regular wave with a wave period, $T=1.3 \mathrm{~s}$, and a wave height, $H=0.10 \mathrm{~m}$. Interaction between regular wave and vertical breakwater was analyzed for four different water depths, $d$, varying from $0.325 \mathrm{~m}$ to $0.266 \mathrm{~m}$, which result in wave lengths, $L$, from $2.023 \mathrm{~m}$ to $1.879 \mathrm{~m}$ (Martins, 2012). For these conditions, it is expected to have an impact load for all cases, according to PROVERBS (1999). Table 1 presents the characteristics of the four analyzed configurations: the wave length, the wave-maker amplitude, $A_{b}$, and the water depth at the toe of the vertical breakwater, $d_{t}$. The tests lasted long enough to generate at least ten regular waves. Active absorption of the reflected waves at the wave-maker was not considered in the present tests since it was not implemented at the numerical model at the stage.

Experimental data was collected in two resistive-type wave gauges (developed at LNEC), and six pressure sensors (model AB/ HP from Honeywell with diaphragm size of $19 \mathrm{~mm}$ and maximum pressure 20,000 PSI). The first gauge (G1) was located at $x=2.643 \mathrm{~m}$ from the wave-maker initial position to verify the generated wave characteristics. The second gauge (G2) was located on the $1: 3$ slope, at $x=3.943 \mathrm{~m}$, to verify wave conditions near the structure. Six pressure sensors were located at the front face of the vertical wall, approximately at the middle of the wall width, to limit the effects of the flume walls. The center of pressure sensor P1 is located $0.055 \mathrm{~m}$ above the berm. The center of sensor P2 is placed $0.055 \mathrm{~m}$ above the center of P1, the center of P3 $0.055 \mathrm{~m}$ above the center of P2, etc. (Fig. 1). Fig. 2 shows the wave flume with the vertical wall and the sensor position.

Eventhough a sampling rate greater than $1 \mathrm{kHz}$ is recommended to measure impact pressure, a frequency of $400 \mathrm{~Hz}$ was used for data acquisition in both wave gauges and pressure sensors due to the available equipment limitations.

Each wave condition was repeated ten times. The several repetitions present a good agreement: before wave re-reflection on the wave-maker for the four configurations and for free surface elevation, the maximum deviation, RMS (root-mean-square), of

Table 1

Characteristics of the four studied configurations of the vertical breakwater

\begin{tabular}{lllll}
\hline Configuration & $d(\mathrm{~m})$ & $L(\mathrm{~m})$ & $A_{b}(\mathrm{~m})$ & $d_{t}(\mathrm{~m})$ \\
\hline 1 & 0.266 & 1.879 & 0.05765 & 0.085 \\
2 & 0.282 & 1.921 & 0.05518 & 0.101 \\
3 & 0.300 & 1.965 & 0.05296 & 0.119 \\
4 & 0.325 & 2.023 & 0.05048 & 0.144 \\
\hline
\end{tabular}

the repetitions (Table 2) were $\pm 0.0017 \mathrm{~m}$ and $\pm 0.0058 \mathrm{~m}$ at gauges G1 and G2, respectively. Errors were larger for G2, the gauge located near the structure, since there stronger non-linear phenomena appear. The second part of Table 2 presents the relative errors, i.e. the percentage of variation expressed as the ration between the RMS and the wave amplitude. The calculated errors are less than $6 \%$ for gauge G1 and between $6 \%$ and $11 \%$ for gauge $\mathrm{G} 2$ due to the proximity of the structure.

Table 3 presents the maximum deviation of the pressure values for the repetitions at P1 to P6 and for the four configurations. Overall pressure deviation shows a good agreement despite its higher RMS values, ranging from $0.82 \times 10^{-2} \mathrm{~m} \mathrm{H}_{2} \mathrm{O}$ to $9.59 \times 10^{-2} \mathrm{~m} \mathrm{H}_{2} \mathrm{O}$. Values of $R M S$ were larger for the pressure sensor that was directly exposed to the impact loads (sensor P1 for configurations 1 and 2 and sensor P2 for configuration 3 and 4). The phenomena involved (impact loads) and the high turbulent nature of the flow combined with the very short duration of the pressure peaks and the variability of the impact point are some reasons for these higher values.

Tables 4, 6, 8 and 10 and 5, 7, 9 and 11 present the first maximum pressure and corresponding RMS at sensors for the first wave impact/interaction on the structure and the corresponding

Table 2

RMS of free surface elevation at gauge G1 and G2 and percentage of variation expressed as the ration between the RMS and the wave amplitude.

\begin{tabular}{|c|c|c|c|c|}
\hline \multirow[t]{2}{*}{$R M S(\mathrm{~m}) \times 10^{-3}$} & \multicolumn{4}{|c|}{ Configuration } \\
\hline & 1 & 2 & 3 & 4 \\
\hline G1 & 1.717 & 2.849 & 2.452 & 2.391 \\
\hline G2 & 5.763 & 5.147 & 3.342 & 3.625 \\
\hline Error \% & 1 & 2 & 3 & 4 \\
\hline G1 & 3.43 & 5.70 & 4.90 & 4.78 \\
\hline G2 & 11.53 & 10.29 & 6.68 & 7.25 \\
\hline
\end{tabular}

Table 3

RMS of pressure at sensors $\mathrm{P} 1$ to $\mathrm{P}_{6}$

\begin{tabular}{lllll}
\hline RMS $\left(\mathrm{mH}_{2} \mathrm{O}\right) \times 10^{-1}$ & \multicolumn{4}{l}{ Configuration } \\
\cline { 2 - 5 } & 1 & 2 & 3 & 4 \\
\hline P1 & 0.679 & 1.049 & 0.737 & 0.111 \\
P2 & 0.293 & 0.786 & 0.894 & 0.121 \\
P3 & 0.183 & 0.223 & 0.126 & 0.111 \\
P4 & 0.135 & 0.154 & 0.128 & 0.087 \\
P5 & 0.123 & 0.132 & 0.099 & 0.095 \\
P6 & 0.134 & 0.144 & 0.123 & 0.088 \\
\hline
\end{tabular}
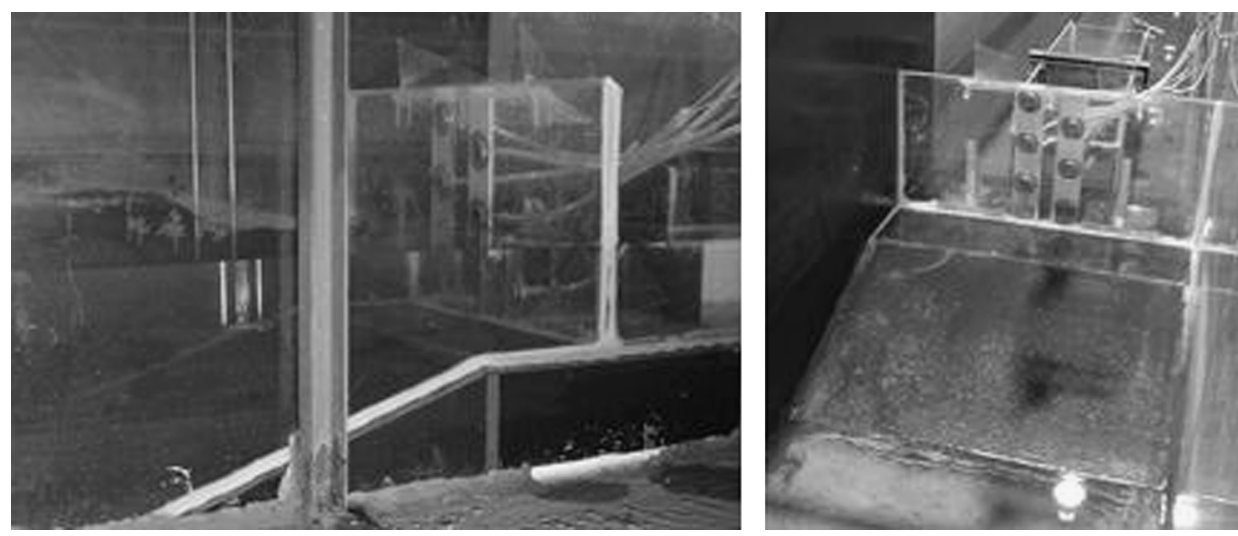

Fig. 2. Composite breakwater at the flume with pressure sensors at the front face. 
Table 4

Maximum pressure and RMS at sensors P1-P3 for wave impact for case 1 $(d=0.266 \mathrm{~m})$.

\begin{tabular}{lllll}
\hline Pressure sensor & $\left(\mathrm{mH}_{2} \mathrm{O}\right) \times 10^{-1}$ & \multicolumn{3}{l}{ Wave impact } \\
\cline { 3 - 5 } & & 1 & 2 & 3 \\
\hline P1 & $P_{\text {Max }}$ & 3.93 & 1.71 & 1.91 \\
& $R M S$ & 0.679 & 0.636 & 0.584 \\
P2 & $P_{\text {Max }}$ & 1.17 & 0.82 & 0.84 \\
& $R M S$ & 0.293 & 0.161 & 0.152 \\
P3 & $P_{\text {Max }}$ & 1.05 & 0.93 & 0.81 \\
& $R M S$ & 0.183 & 0.196 & 0.136 \\
\hline
\end{tabular}

Table 5

Percentage of variation expressed as the ration between the RMS and the maximum pressure at sensors P1-P3 for the wave impact at case $1(d=0.266 \mathrm{~m})$.

\begin{tabular}{lllc}
\hline Pressure sensor & \multicolumn{2}{l}{ Wave impact } \\
\cline { 2 - 4 } & 1 & 2 & 3 \\
\hline P1 & 17.28 & 37.19 & 30.37 \\
P2 & 25.04 & 19.63 & 18.10 \\
P3 & 17.43 & 21.08 & 17.00 \\
\hline
\end{tabular}

Table 6

Maximum pressure and RMS at sensors P1-P3 for wave impact at case 2 $(d=0.282 \mathrm{~m})$

\begin{tabular}{lllll}
\hline Pressure sensor & $\left(\mathrm{mH}_{2} \mathrm{O}\right) \times 10^{-1}$ & \multicolumn{2}{l}{ Wave impact } \\
\cline { 3 - 5 } & & 1 & 2 & 3 \\
\hline P1 & $P_{\text {Max }}$ & 1.39 & 3.33 & 4.12 \\
& $R M S$ & 0.204 & 0.569 & 1.049 \\
P2 & $P_{\text {Max }}$ & 1.62 & 1.31 & 1.56 \\
& $R M S$ & 0.786 & 0.420 & 0.262 \\
P3 & $P_{\text {Max }}$ & 0.83 & 0.84 & 0.77 \\
& RMS & 0.159 & 0.223 & 0.122 \\
\hline
\end{tabular}

Table 7

Percentage of variation expressed as the ration between the RMS and the maximum pressure at sensors P1-P3 for wave impact at case $2(d=0.282 \mathrm{~m})$

\begin{tabular}{llcc}
\hline Pressure sensor & \multicolumn{2}{l}{ Wave impact } \\
\cline { 2 - 4 } & 1 & 2 & 3 \\
\hline P1 & 14.68 & 17.09 & 25.46 \\
P2 & 48.52 & 32.06 & 16.79 \\
P3 & 19.16 & 26.55 & 15.84 \\
\hline
\end{tabular}

percentage of variation expressed as the ratio between the RMS and the maximum pressure at the sensors, respectively. The errors obtained for the first pressure peak (maximum), corresponding to the first impact or interaction between the incident wave and the vertical wall, present values ranging from $10 \%$ to $50 \%$. These values indicate the variability of the complex phenomenon which occurs during wave-structure interaction that can vary between test repetitions. This fact demonstrates the difficulty to reproduce numerically the measured pressure.

Differences on the free surface level and on the pressure were larger after the re-reflection phenomena on the wave-maker and were not considered for the present analysis.
Table 8

Maximum pressure and RMS at sensors P1-P4 for wave impact for case 3 $(d=0.300 \mathrm{~m})$

\begin{tabular}{lllll}
\hline Pressure sensor & $\left(\mathrm{mH}_{2} \mathrm{O}\right) \times 10^{-1}$ & \multicolumn{3}{l}{ Wave impact } \\
\cline { 3 - 5 } & & 1 & 2 & 3 \\
\hline P1 & $P_{\operatorname{Max}}$ & 0.71 & 2.29 & 1.92 \\
& $R M S$ & 0.110 & 0.583 & 0.737 \\
P2 & $P_{\text {Max }}$ & 0.83 & 2.11 & 2.54 \\
& $R M S$ & 0.086 & 0.894 & 0.365 \\
P3 & $P_{\operatorname{Max}}$ & 0.93 & 0.74 & 0.77 \\
& $R M S$ & 0.126 & 0.085 & 0.095 \\
P4 & $P_{\operatorname{Max}}$ & 0.79 & 0.064 & 0.052 \\
& $R M S$ & 0.128 & 0.095 & 0.069 \\
\hline
\end{tabular}

Table 9

Percentage of variation expressed as the ration between the RMS and the maximum pressure at sensors P1-P4 for wave impact at case $3(d=0.300 \mathrm{~m})$.

\begin{tabular}{llcc}
\hline Pressure sensor & \multicolumn{3}{l}{ Wave impact } \\
\cline { 2 - 4 } & 1 & 2 & 3 \\
\hline P1 & 15.52 & 25.35 & 38.49 \\
P2 & 10.40 & 42.34 & 14.43 \\
P3 & 13.54 & 11.56 & 12.35 \\
P4 & 16.37 & 14.84 & 13.38 \\
\hline
\end{tabular}

Table 10

Maximum pressure and RMS at sensors P1-P4 for wave impact at case 4 $(d=0.325 \mathrm{~m})$

\begin{tabular}{lllll}
\hline Pressure sensor & $\left(\mathrm{mH}_{2} \mathrm{O}\right) \times 10^{-1}$ & \multicolumn{3}{l}{ Wave impact } \\
\cline { 3 - 5 } & & 1 & 2 & 3 \\
\hline \multirow{2}{*}{ P1 } & $P_{\text {Max }}$ & 0.647 & 0.737 & 0.758 \\
& $R M S$ & 0.087 & 0.108 & 0.111 \\
P2 & $P_{\text {Max }}$ & 0.721 & 0.805 & 0.732 \\
& $R M S$ & 0.075 & 0.121 & 0.094 \\
P3 & $P_{\text {Max }}$ & 0.794 & 0.689 & 0.761 \\
& $R M S$ & 0.097 & 0.101 & 0.111 \\
P4 & $P_{M a x}$ & 0.631 & 0.852 & 0.720 \\
& $R M S$ & 0.062 & 0.087 & 0.057 \\
\hline
\end{tabular}

Table 11

Percentage of variation expressed as the ration between the RMS and the maximum pressure at sensors P1-P4 for wave impact at case $4(d=0.325 \mathrm{~m})$.

\begin{tabular}{lllr}
\hline Pressure sensor & \multicolumn{2}{l}{ Wave impact } & 3 \\
\cline { 2 - 4 } & 1 & 2 & 14.64 \\
& & 14.65 & 12.84 \\
P1 & 13.45 & 15.13 & 14.61 \\
P2 & 10.42 & 14.66 & 7.92 \\
P3 & 12.22 & 10.24 & \\
P4 & 9.84 & & \\
\hline
\end{tabular}

\section{Numerical modeling of wave impact on a vertical wall}

The weakly-compressible SPH numerical model was used for modeling impact loads on a vertical wall. Wave generation was performed by a piston-type numerical wave-maker with the same amplitude of the sinusoidal movement imposed at the physical model.

The partial filtering density technique was applied to particles from $x=4.086 \mathrm{~m}$ (middle of the $1: 3$ slope) to the end of the numerical domain (Martins, 2012; Didier et al., 2013) and each 30 time iterations (Gómez-Gesteira et al., 2008). 
For the present simulations the number of fluid and solid particles used depended on the water depth in the flume and is indicated in Table 12. Convergence study for the particle dimensions, performed by Didier et al. (2013), indicates that a resolution of at least 36-40 particles per wave height is necessary for an accurate modeling of the wave propagation and impact loads on vertical wall. This criterion was respected in the present study to define the number of the particles for each tested configuration.

For case $1, d=0.266 \mathrm{~m}$, the total number of particles was 154735. For this case, the mean time step was around $2.4 \times 10^{-5} \mathrm{~s}$. Computational time was $83 \mathrm{~h}$ for modeling $8.5 \mathrm{~s}$, using a serial version of the code and a Personal Computer Intel (R) Core(TM) i7 CPU 930 @ $2.80 \mathrm{GHz}$.

The numerical and the physical modeling was performed without dynamic absorption of the wave-maker, so the result analysis was conducted before re-reflection of the wave on the wave-maker reached the breakwater, corresponding to four wave impacts on the breakwater. Thus, the numerical simulations were performed until $8.5 \mathrm{~s}$.

Figs. 3-10 show the mean time series of free surface elevation at gauges $\mathrm{G} 1$ and $\mathrm{G} 2$, and pressure at sensors P1-P4, for the wave height $H=0.10 \mathrm{~m}$, the wave period $T=1.3 \mathrm{~s}$ and for the water depth at the toe of the vertical breakwater, $d_{t}$, varying from $0.085 \mathrm{~m}$ to $0.144 \mathrm{~m}$ (Table 1). At sensors P5 and P6 less wave impact occurred, producing less relevant results for the analyses. Time series of the numerical results were compared with the average of the experimental data time series (i.e. average of the 10 test repetitions).

Table 12

Dimension of particles, $d_{o}$, smoothing length, $h$, and number of particles for the four configurations.

\begin{tabular}{lllll}
\hline Configuration & $d(\mathrm{~m})$ & $d_{o}(\mathrm{~m})$ & $h(\mathrm{~m})$ & No. of particles \\
\hline 1 & 0.266 & 0.0026600 & 0.0034609 & 154735 \\
2 & 0.282 & 0.0026604 & 0.0034614 & 164530 \\
3 & 0.300 & 0.0026549 & 0.0034542 & 176327 \\
4 & 0.325 & 0.0026639 & 0.0034660 & 190465 \\
\hline
\end{tabular}

a

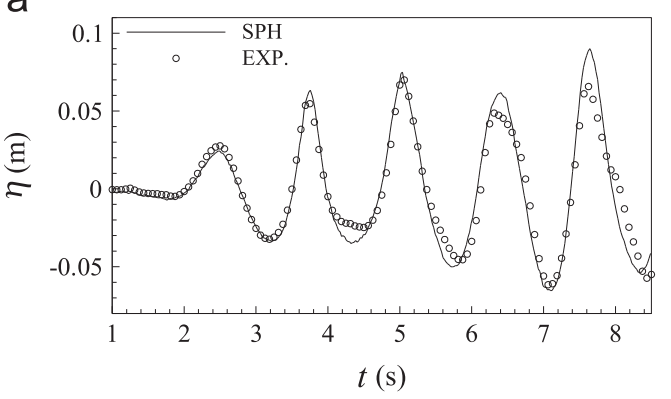

b

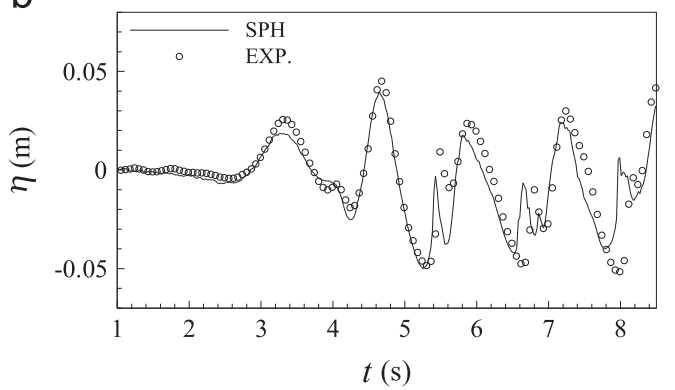

Fig. 3. Free surface elevation for $d=0.266 \mathrm{~m}$, (a) gauges $\mathrm{G} 1$ (b) and G2.

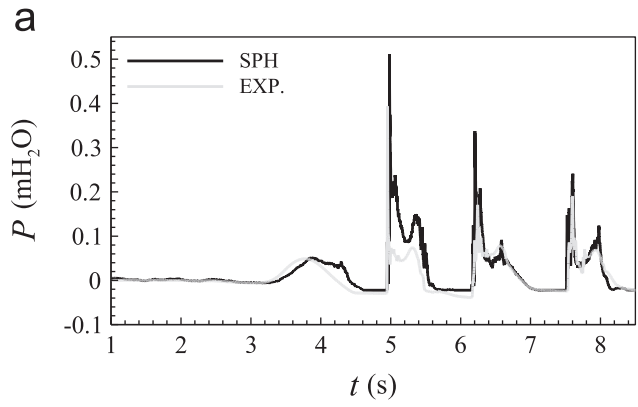

b
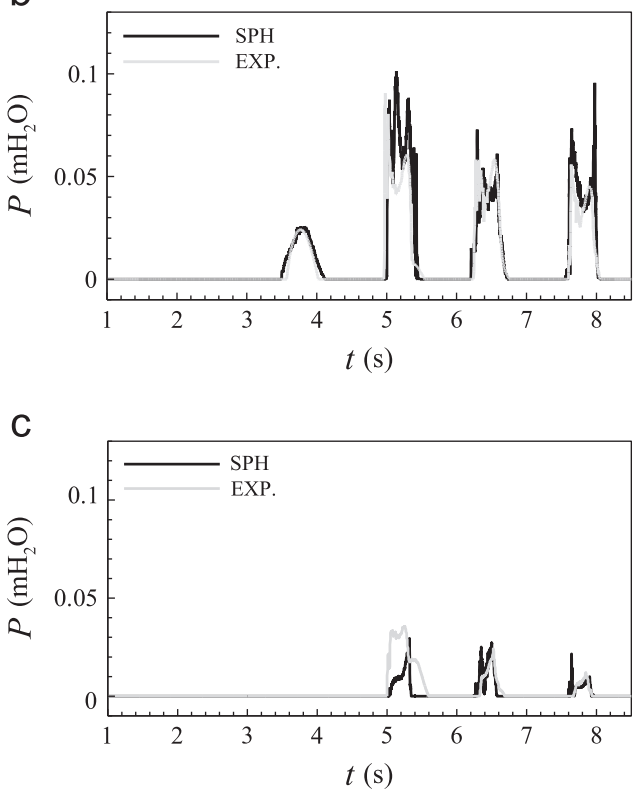

Fig. 4. Pressure on sensor for $d=0.266 \mathrm{~m}$, (a) P1, (b) P2, and (c) P3.
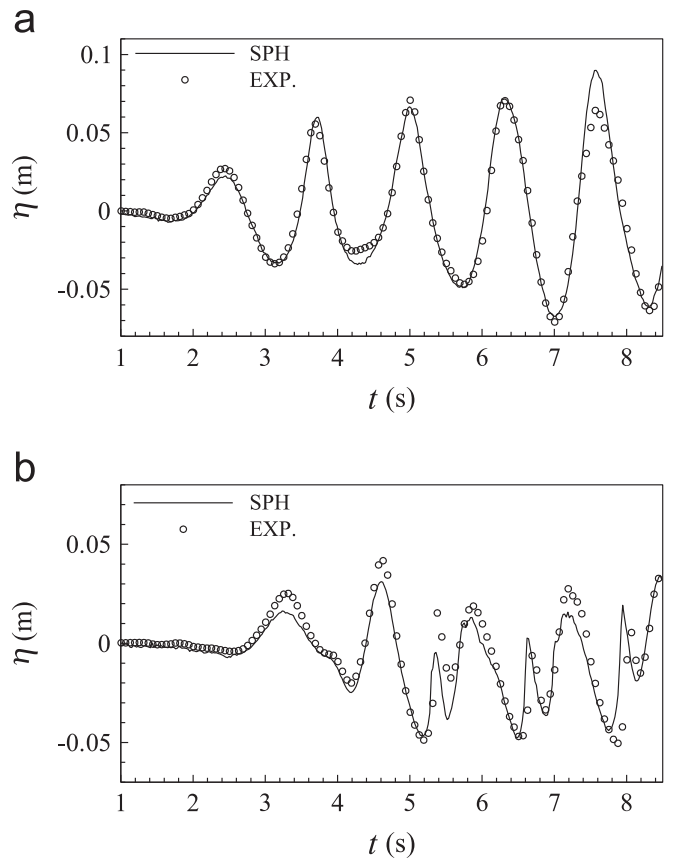

Fig. 5. Free surface elevation for $d=0.282 \mathrm{~m}$, (a) gauges G1 and (b) G2.

Figs. 3, 5, 7, and 9 present the time series of the numerical and experimental free surface elevations at gauges G1 and G2. A good agreement was globally observed between numerical results and 


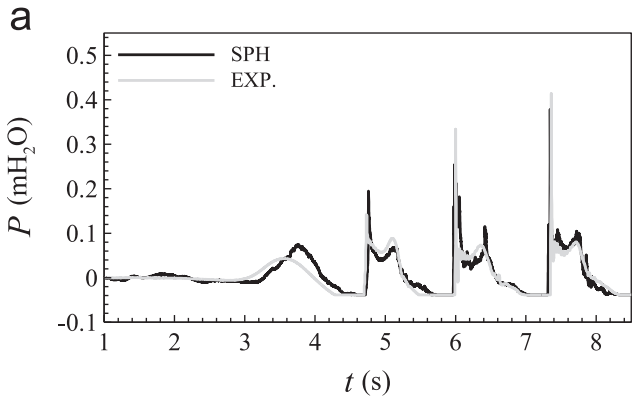

b
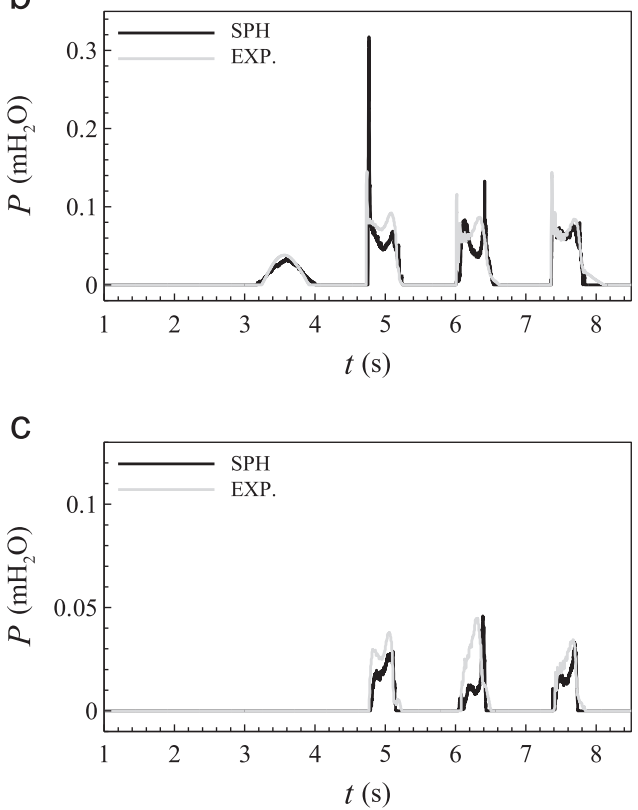

Fig. 6. Pressure on sensor for $d=0.282 \mathrm{~m}$, (a) P1, (b) P2, and (c) P3.

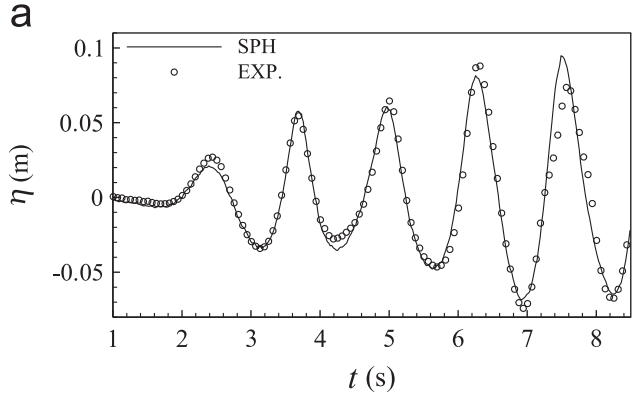

b

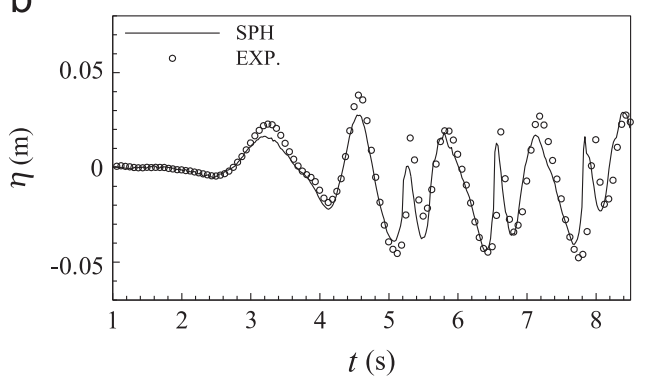

Fig. 7. Free surface elevation for $d=0.300 \mathrm{~m}$, (a) gauges $\mathrm{G} 1$ and (b) G2.

experimental data for gauges G1 and G2: for all the tested water depths the free surface elevation pattern was correctly simulated. The differences between numerical and experimental results at
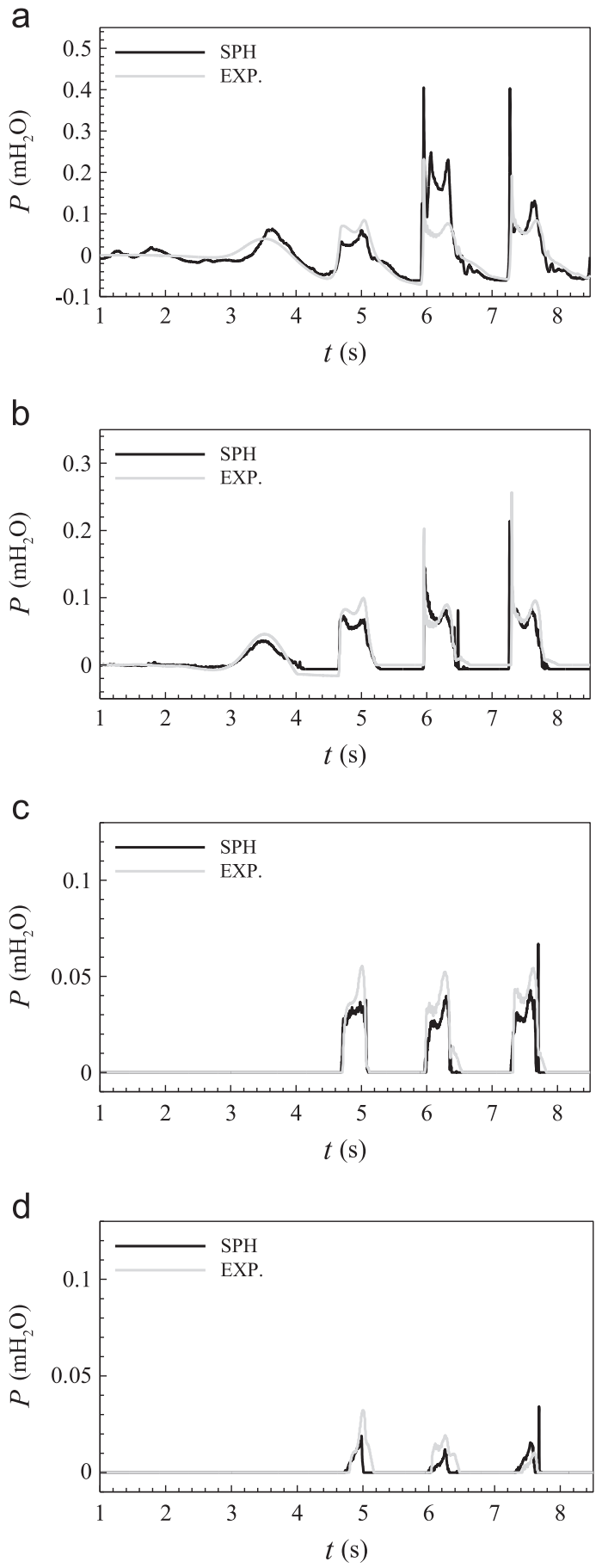

Fig. 8. Pressure on sensor for $d=0.300 \mathrm{~m}$, (a) P1, (b) P2, (c) P3, and (d) P4.

gauges G1 and G2 were slightly larger for the crests and troughs. For the percentage of variation, expressed as the ratio between the RMS and the wave amplitude, the same trend was observed comparing numerical and experimental results (Table 2 and 13).

Figs. 4, 6, 8 and 10 present the time series of numerical and experimental pressure at the pressure sensors P1, P2 and P3 (Figs. 4 and 6) and P1, P2, P3 and P4 (Figs. 8 and 10). Numerical pressure time series exhibit some noise, even when using the partial re-normalization of particle density and a ten pass of smoothing was applied using an average smoothing on ten neighboring points. Pressure variation trend at sensors P1-P4 obtained with the numerical model was globally similar to the experimental data. Agreement between numerical and experimental results was good regarding 
a

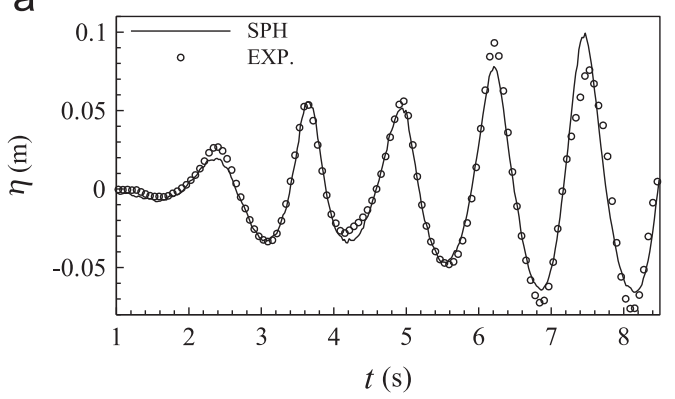

b

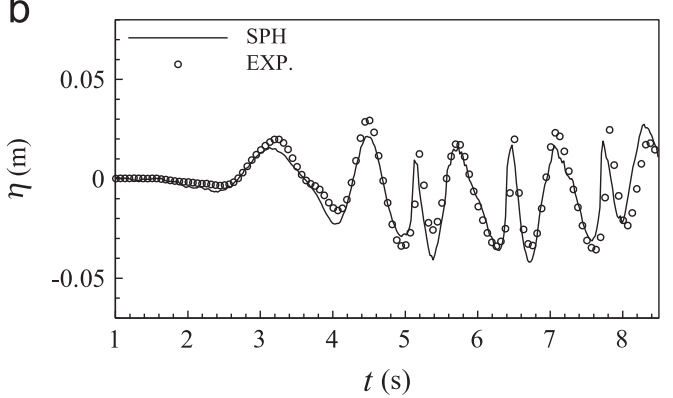

Fig. 9. Free surface elevation for $d=0.325 \mathrm{~m}$, (a) gauges $\mathrm{G} 1$ and (b) G2.

the complexity of the interaction between waves that break and impact on the vertical wall. The major differences obtained were in the maximum value of the first impact. These differences can be due to an insufficient data acquisition frequency at the experimental tests, making it difficult to catch the maximum pressure due to its very short duration, less than $0.01 \mathrm{~s}$, and to numerical modeling limitations, such as the absence of the air in the modeling. For this first impact, the differences can reach $50 \%$, same order of magnitude of the differences found between test repetitions, since a slightly difference in one of the phenomenon occurred during the wave-structure interaction leading to a large difference on pressure values at the structure.

Fig. 11 shows the horizontal force at the wall for the four water depths. Forces on the vertical wall of the breakwater have the same trend as those predicted in the project PROVERBS (1999): a first impact load with a high force value occurs during a short period of time; a second maximum of force, with lower intensity, occurs due to the collapse of the water column at the wall after the first impact.

Tables 13 and 14 present, for the four tested water depths, a statistical analysis of the time series of the free surface elevation at G1 and G2 and of the pressure at P1-P4, respectively. Comparing the numerical results with the experimental data, the Bias (mean deviation), RMS (root-mean-square) and IC (index of agreement) parameter are presented (Willmott et al., 1985) as well as the error, i.e. percentage of variation expressed as the ratio between the Bias and RMS considering the incident wave amplitude.

Bias for free surface elevation at gauges G1 and G2 shows that the numerical model slightly underestimate the free surface elevation. RMS for gauge G2 tends to be greater than for G1. Near the structure, where gauge G2 was located, free surface elevation was more variable due to the complexity and variability of the wave breaking, wave reflection, and collapse of the water column in this zone. Percentage of variation expressed as the ratio between Bias and RMS and wave amplitude was inferior to $12 \%$ and $24 \%$, respectively. For the RMS the ratio was larger than the ratio of the tested repetitions (Table 2) and larger at gauge G2 than G1. The IC for gauge G1 was about $99 \%$. For gauge G2, IC was smaller than for G1, presenting values around $90-93 \%$.
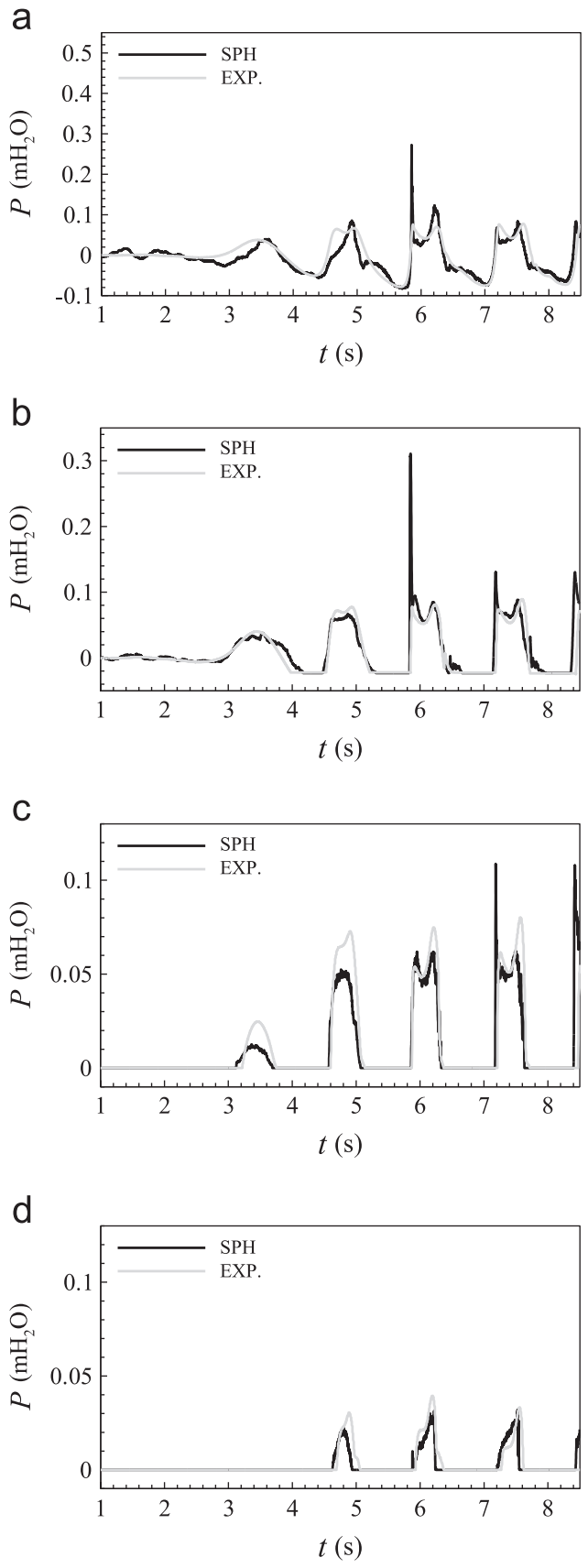

Fig. 10. Pressure on sensor for $d=0.325 \mathrm{~m}$, (a) P1, (b) P2, (c) P3, and (d) P4.

The Bias of the pressure results does not present a defined tendency. Nevertheless, Bias tends to be positive for sensor P1, where impact loads occur, and negative for P3 and P4. This result evidences that the numerical model overestimates the pressure for the impact loads and underestimates the pressure along the wall after wave impact. RMS for the pressure results decreases from sensors P1 to P4 for all configurations. Impact loads occur essentially at the inferior part of the vertical wall, where P1 and P2 were located. Time series of pressure at sensor P1 and P2 show large variation of the pressure peak corresponding to wave impacts on that zone of the vertical wall. This explains why RMS was greater for sensors P1 and P2 than for sensors P3 and P4. These results are also coherent with the experimental RMS results obtained from the tests repetitions, Table 3. Experimental RMS values were greater for sensors P1 and P2 than for P3 and P4, indicating the variability of the pressure measured at that sensors, 
a

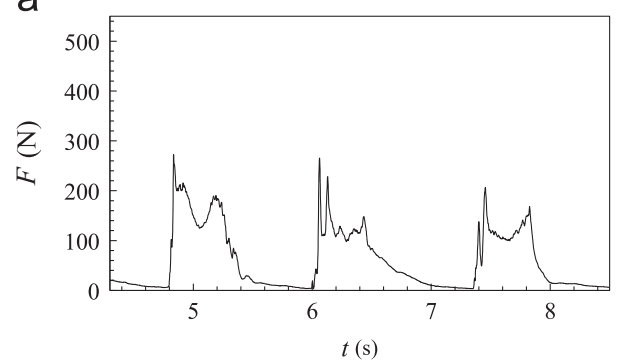

b

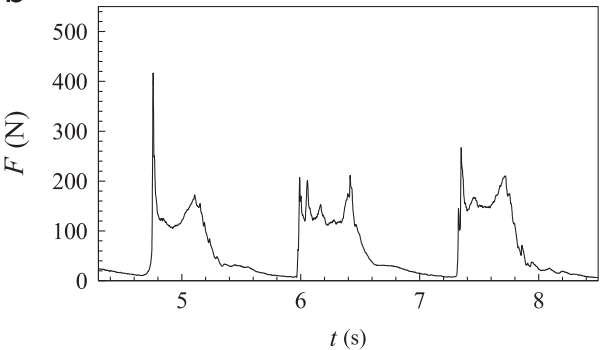

C

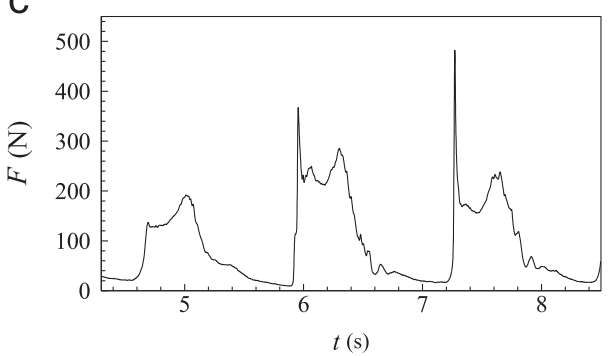

d

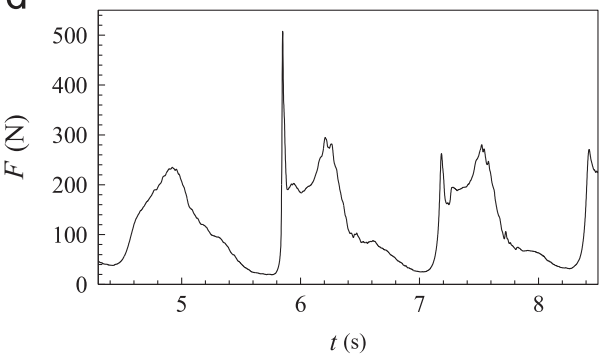

Fig. 11. Time series of horizontal force at the vertical wall for the four configurations: (a) $d=0.266 \mathrm{~m}$, (b) $d=0.282 \mathrm{~m}$, (c) $d=0.300 \mathrm{~m}$, and (d) $d=0.325 \mathrm{~m}$.

particularly exposed to the impact loads. IC values range from $68.8 \%$ to $94.4 \%$, confirming that the estimation of pressure was relatively good regarding the very complex phenomena occurring during the impact loads. In fact, agreement between numerical and experimental results of pressure is very difficult since small differences in the incident wave and/or in the wave-breaking can lead to different impact position on the vertical wall, thus leading to large differences on the pressure obtained at both numerical and experimental models.

The horizontal force on the vertical wall obtained through the pressure integration is easier to compare than the pressure at a specific sensor and it is a parameter used in structure design. However, since the experimental wave flume was not equipped for measuring force this comparison could not be made.

Regarding the average statistical values, i.e. the average obtained from the values presented in Tables 5 and 6, average RMS for the free surface elevation and pressure were about $0.0091 \mathrm{~m}$ and $0.0164 \mathrm{~m} \mathrm{H}_{2} \mathrm{O}$, respectively. Average IC for the free

Table 13

Statistic values (Bias, RMS and $I C$ ) for the free surface elevation at gauges G1 and G2 for water depths $0.266,0.282,0.300$ and $0.325 \mathrm{~m}$ and percentage of variation expressed as the ratio between Bias and RMS and the incident wave amplitude.

\begin{tabular}{|c|c|c|c|c|}
\hline \multirow[t]{2}{*}{$\operatorname{Bias}(\mathrm{m}) \times 10^{-3}$} & \multicolumn{4}{|c|}{ Configuration } \\
\hline & 1 & 2 & 3 & 4 \\
\hline G1 & -0.65 & -3.67 & -5.96 & -1.07 \\
\hline G2 & -2.27 & -2.77 & -0.76 & -1.05 \\
\hline Error \% & 1 & 2 & 3 & 4 \\
\hline G1 & 1.30 & 7.34 & 11.92 & 2.14 \\
\hline G2 & 4.54 & 5.54 & 1.52 & 2.10 \\
\hline \multirow[t]{2}{*}{$R M S(\mathrm{~m}) \times 10^{-2}$} & \multicolumn{4}{|c|}{ Configuration } \\
\hline & 1 & 2 & 3 & 4 \\
\hline G1 & 0.900 & 0.678 & 0.867 & 0.823 \\
\hline G2 & 1.188 & 0.986 & 1.033 & 0.800 \\
\hline Error \% & 1 & 2 & 3 & 4 \\
\hline G1 & 18.00 & 13.56 & 17.34 & 16.46 \\
\hline G2 & 23.76 & 19.72 & 20.66 & 16.00 \\
\hline \multirow[t]{2}{*}{ IC } & \multicolumn{4}{|c|}{ Configuration } \\
\hline & 1 & 2 & 3 & 4 \\
\hline G1 & 0.982 & 0.991 & 0.987 & 0.988 \\
\hline G2 & 0.905 & 0.933 & 0.918 & 0.935 \\
\hline
\end{tabular}

Table 14

Statistic values (Bias, RMS and IC) for the pressure at sensors P1-P4 for water depths $0.266,0.282,0.300$ and $0.325 \mathrm{~m}$.

\begin{tabular}{|c|c|c|c|c|}
\hline \multirow[t]{2}{*}{$\operatorname{Bias}(\mathrm{m}) \times 10^{-3}$} & \multicolumn{4}{|c|}{ Configuration } \\
\hline & 1 & 2 & 3 & 4 \\
\hline P1 & 9.939 & 3.011 & 3.873 & -4.772 \\
\hline & 1.453 & -2.810 & -3.180 & 3.776 \\
\hline & -1.202 & -1.562 & -1.841 & -1.984 \\
\hline & - & - & -0.785 & -0.765 \\
\hline \multirow[t]{2}{*}{$R M S(\mathrm{~m}) \times 10^{-2}$} & \multicolumn{4}{|c|}{ Configuration } \\
\hline & 1 & 2 & 3 & 4 \\
\hline P1 & 3.483 & 2.495 & 3.858 & 2.214 \\
\hline P2 & 0.958 & 1.598 & 1.856 & 2.810 \\
\hline P3 & 0.526 & 0.599 & 0.590 & 1.207 \\
\hline P4 & - & - & 0.389 & 0.450 \\
\hline \multirow[t]{2}{*}{ IC } & \multicolumn{4}{|c|}{ Configuration } \\
\hline & 1 & 2 & 3 & 4 \\
\hline P1 & 0.817 & 0.896 & 0.844 & 0.922 \\
\hline P2 & 0.927 & 0.906 & 0.908 & 0.834 \\
\hline P3 & 0.741 & 0.848 & 0.944 & 0.913 \\
\hline P4 & - & - & 0.688 & 0.887 \\
\hline
\end{tabular}

surface elevation and pressure were about $95.5 \%$ and $86.2 \%$, respectively. Taking into account the complex phenomena involved, very difficult to be accurately modeled, both numerically and physically, the differences obtained between physical and numerical results are relatively small and numerical SPH model can be considered as a very promising tool for modeling interaction between waves and coastal structures.

Figs. 12 and 13 illustrate the process of the wave impact on the vertical wall for the water depths $d=0.282$ and $0.325 \mathrm{~m}$, respectively. From Figs. 12 and 13 it can be concluded that the SPH snapshots are qualitatively similar to the laboratory photographs and a good similarity of the numerical calculations and the experimental photographs can be observed. The development and impact of the wave on the vertical wall of the breakwater, 
a

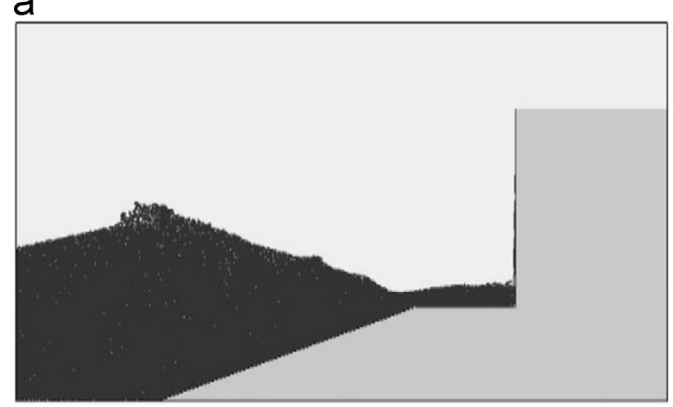

b

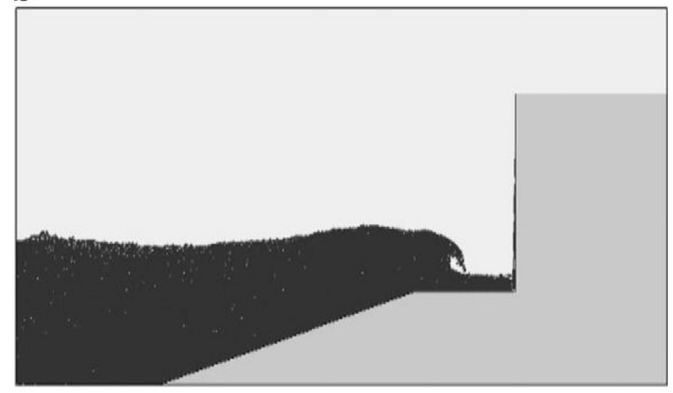

C

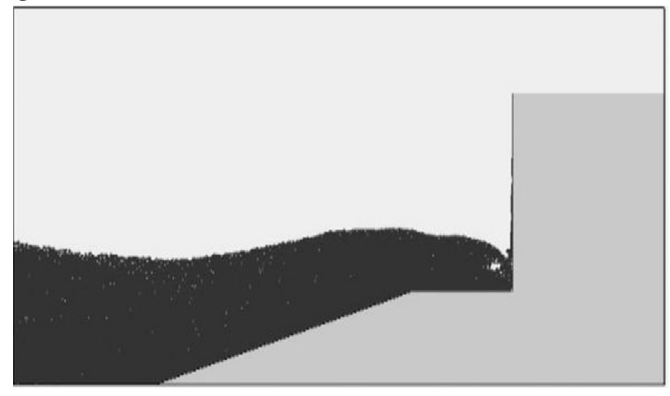

d

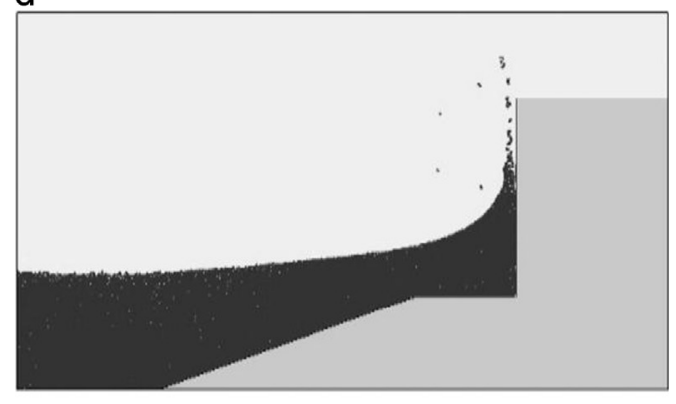

e

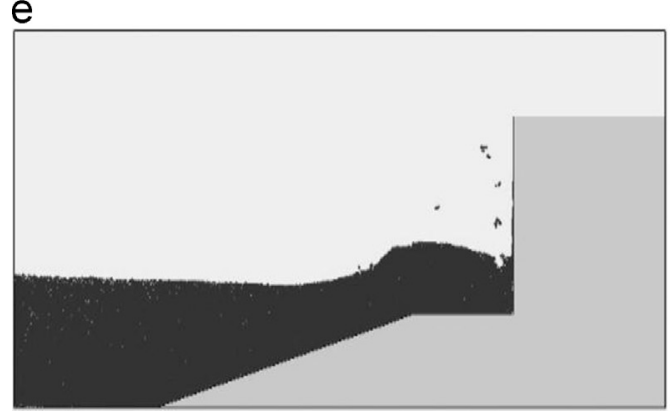

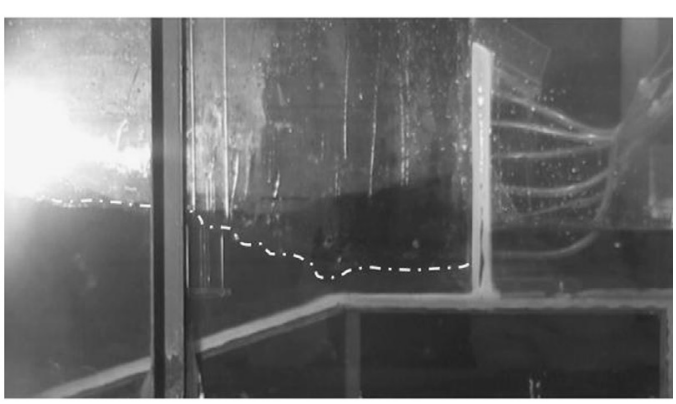
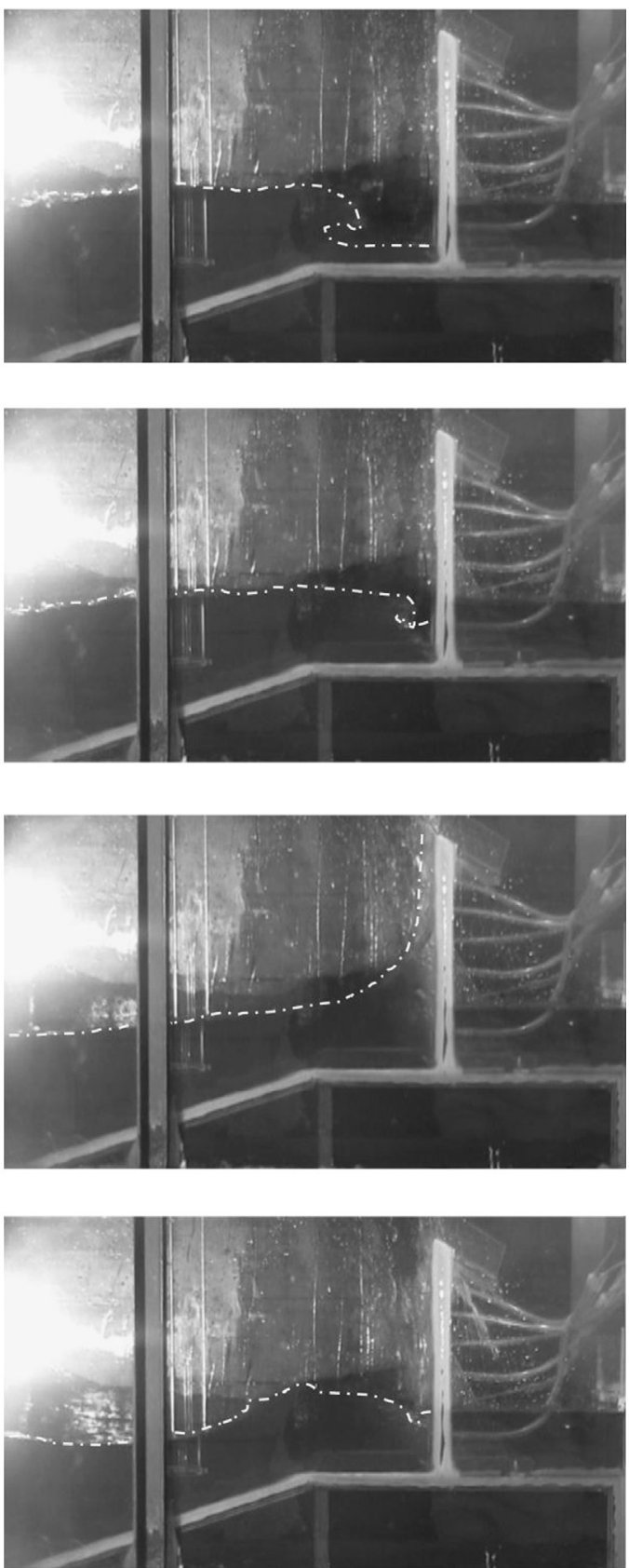

Fig. 12. Snapshots of water particles (on the right) and laboratory photographs (on the left), $T=1.3 \mathrm{~s}, H=0.10 \mathrm{~m}, d=0.282 \mathrm{~m}$, at time (a) 7.03, (b) 7.27, (c) 7.34, (d) 7.58, and (e) $7.82 \mathrm{~s}$.

together with the resulting splash-up process, are well reproduced even if the highly non-linear splash-up process could not be simulated at all. The presented figures not only underline the enhanced accuracy of the SPH numerical model, but also demonstrate the potentiality of the smoothed particle methods as capable methods for hydrodynamic calculations. 
a

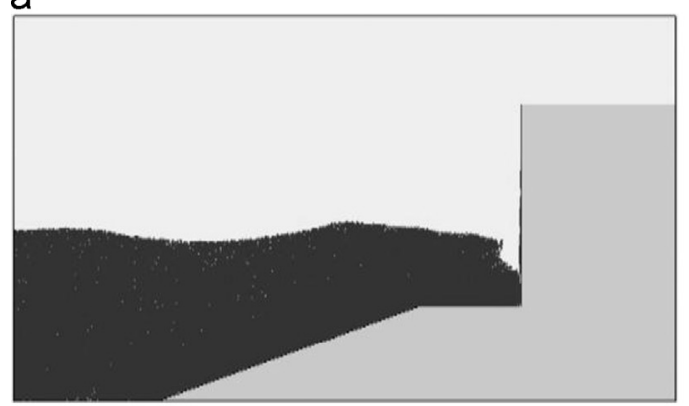

b

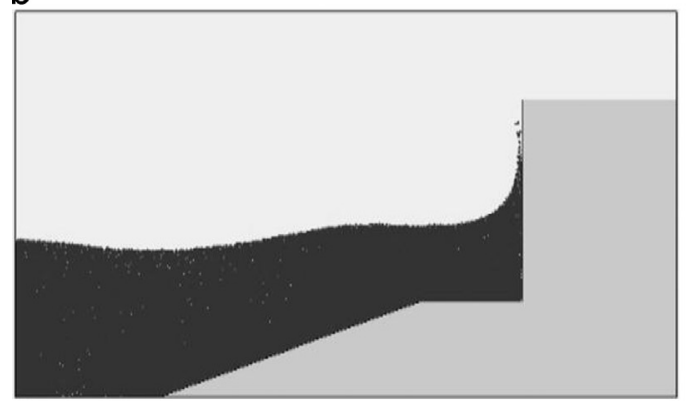

C

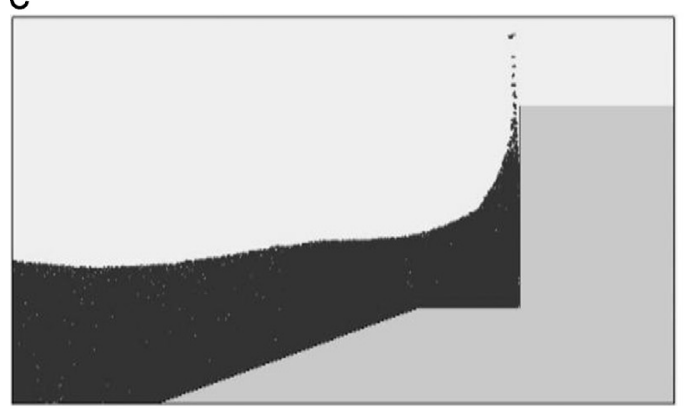

d

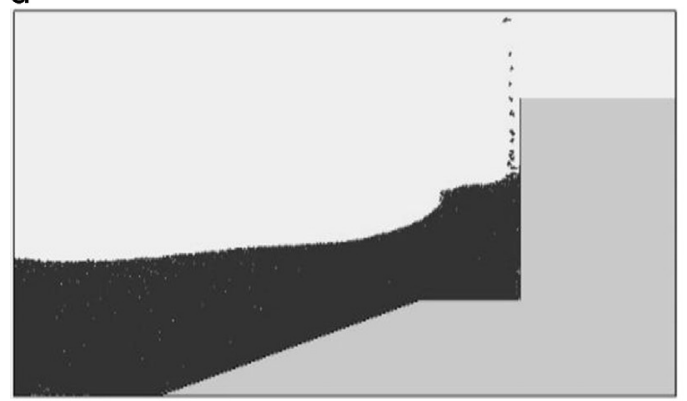

e

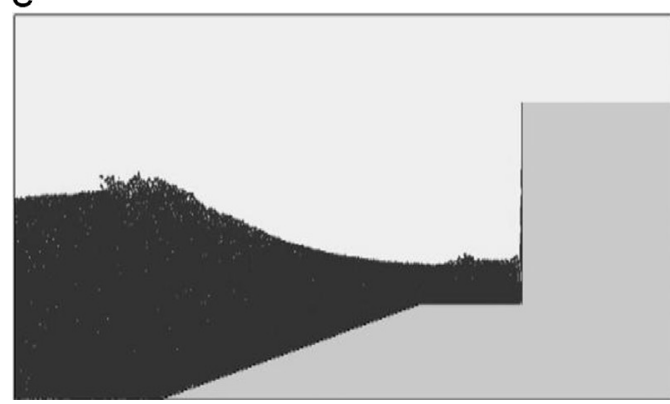

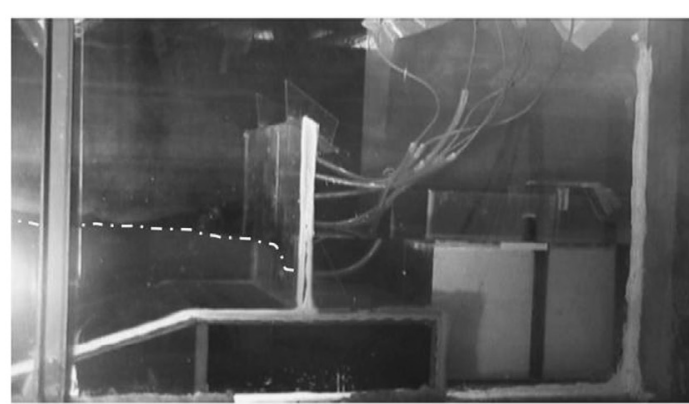
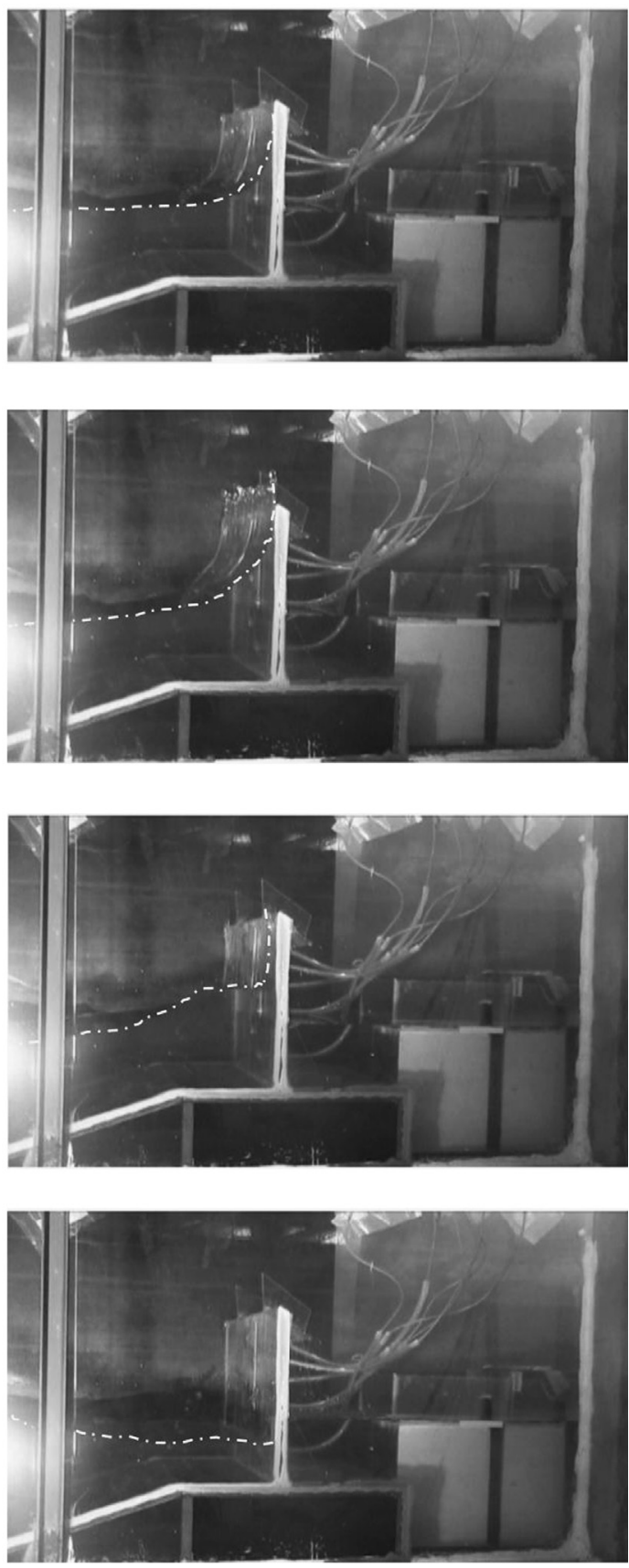

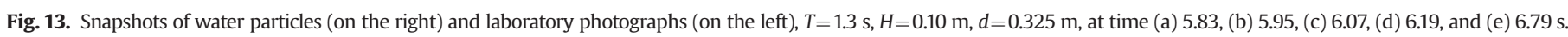

\section{Conclusions}

The paper presents the validation of the SPH numerical model to the study of the wave interaction with a vertical wall of a breakwater. To achieve this validation, a set of tests were performed in a LNEC wave flume. With the purpose of comparing numerical results with experimental data, the flume dimensions were the same for both the numerical and the physical model and 
wave generation was identically made using a piston-type wavemaker.

A successful agreement was found between numerical results and experimental data regarding the free surface elevation at two gauges, G1 and G2, and the pressure at sensors P1-P4 for an incident wave with a period of $1.3 \mathrm{~s}$, wave height of $0.10 \mathrm{~m}$ and four different water depths of $0.266,0.282,0.300$ and $0.325 \mathrm{~m}$.

The force behavior on the vertical wall of the breakwater presents the same trend than the predicted in the project PROVERBS for impact loads: a first impact with a high force intensity during a very short time and a second maximum of pressure, due to the collapse of the water column formed at the wall after the first impact, smaller than the first one.

Regarding the average statistical value IC (average of the IC obtained at gauge and pressure sensor), average IC for free surface flow and pressure were about $95.5 \%$ and $86.2 \%$, respectively. These results depend highly on wave breaking, and on the difficulty of capturing the high pressure peaks explain the differences obtained for the pressure results. Nevertheless, the set of complex phenomena involved are very hard to be accurately modeled, both numerically and physically. Consequently the differences obtained between physical and numerical results can be considered admissible. The evolution of the forces, pressure, and free surface elevation in time were well modeled.

\section{Acknowledgment}

The first author acknowledge the financial support of the Portuguese foundation for the science and technology (Fundação para a Ciência e a Tecnologia - FCT) SFRH/BPD/37901/2007. The authors acknowledge the FCT for the financial support through the project PTDC/ECM/114109/2009, "SPACE - A Smoothed Particle Hydrodynamic model development and validation for coastal engineering applications".

\section{References}

Batchelor, G.K., 1974. Introduction to Fluid Dynamics. Cambridge University Press, UK.

Colagrossi, A., Landrini, M., 2003. Numerical simulation of interfacial flows by smoothed particle hydrodynamics. J. Comput. Phys. 191, 448-475.

Crespo, A.J.C., 2008. Application of the Smoothed Particle Hydrodynamics Model SPHysics to Free-surface Hydrodynamics (Ph.D. thesis). Universidade de Vigo, Spain.

Crespo, A.J.C., Gómez-Gesteira, M., Carracedo, P., Dalrymple, R.A., 2008. Hybridation of generation propagation models and SPH model to study severe sea states in galician coast. J. Mar. Syst. 72, 135-144.

Cuomo, G., Allsop, W., Takahashi, S., 2010. Scaling wave impact pressures on vertical walls. Coast. Eng. 57, 604-609.

Dalrymple, R.A., Rogers, B.D., 2006. Numerical modeling of water waves with the SPH method. Coast. Eng. 53 (2-3), 141-147.

Didier, E., Neves, M.G., 2008. Estudo da interacção onda-estrutura utilizando um modelo numérico Lagrangiano. Rev. Recursos Hidricos 29 (2), 15-26 (in portuguese).

Didier, E., Neves, M.G., 2009a. Wave overtopping of a typical coastal structure of the Portuguese coast using a SPH model. J. Coast. Res. SI 56, 496-500.

Didier E., Neves, M.G., 2009b. Coastal flow simulation using SPH: Wave overtopping on an impermeable coastal structure. In: Proceedings of the 4th International SPHERIC Workshop, Nantes, France, pp. 357-364.
Didier, E., Neves, M.G., 2010a. Study of wave interaction with coastal structures using a SPH numerical model. J. Integr. Coast. Zone Manag. 10 (4), 435-455.

Didier E., Neves, M.G., 2010b. A Lagrangian Smoothed Particles Hydrodynamics $\mathrm{SPH}$ - method for modeling waves-coastal structure interaction. In: Proceedings of the CFD2010 ECCOMAS, Lisboa, Portugal.

Didier, E., Martins, R., Neves M.G., Vasco, J., 2011. Interaction between wave and coastal structure: validation of two Lagrangian numerical models with experimental results. In: Proceedings of MARINE 2011 - Computational Methods in Marine Engineering IV, Lisbon, Portugal, pp. 134-145.

Didier, E., Neves, M.G., 2012. A semi-infinite numerical wave flume using smoothed particle hydrodynamics. Int. J. Offshore Polar Eng. 22 (3), 193-199.

Didier, E., Martins, R., Neves, M.G., 2013. Numerical and experimental modeling of regular wave interacting with a composite breakwater. Int. J. Offshore Polar Eng. 23 (1), 46-54.

Gingold, R.A., Monaghan, J.J., 1977. Smoothed particle hydrodynamics: theory and application to non-spherical stars. Mon. Not. R. Astron. Soc. 181, 375-389.

Gómez-Gesteira, M., Rogers, B.D., Dalrymple, R.A., Crespo, A.J.C., Narayanaswamy, M., 2008. User Guide for the SPhysics Code, version 1.4. 〈http://wiki.manche ster.ac.uk/sphysics $\rangle$.

Gómez-Gesteira, M., Rogers, B.D., Dalrymple, R.A., Crespo, A.J.C., 2010. State-of-theart of classical SPH for free-surface flows. J. Hydraul. Res. 48 (extra issue), 6-27.

Gomez-Gesteira, M., Rogers, B.D., Crespo, A.J.C., Dalrymple, R.A., Narayanaswamy, M., Dominguez, J.M., 2012. SPHysics - development of a free-surface fluid solver - Part 1: theory and formulations. Comput. Geosci. 48, 289-299.

Gotoh, H., Shibahara, T., Sakai, T., 2001. Sub-particle-scale turbulence model for the MPS method - Lagrangian flow model for hydraulic engineering. Computational Fluid Dyn. J. 9 (4), 339-347.

Guanche, R., Losada, I.J., Lara, J.L., 2009. Numerical modeling of coastal structures stability. Coast. Eng. 56 (5-6), 543-558.

Higuera, P., Lara, J.L., Losada, I.J., 2014. Three-dimensional interaction of waves and

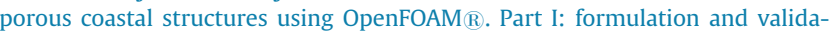
tion. Coast. Eng. 83, 243-258.

Hughes, J.P., Graham, D.I., 2010. Comparison of incompressible and weaklycompressible SPH models for free-surface water flows. J. Hydraul. Res. 48 (extra issue), 105-117.

Johnson, G., Stryk, R., Beissel, S., 1996. SPH for high velocity impact calculations. Comput. Methods Appl. Mech. Eng. 139, 347-373.

Lara, J.L., Losada, I.J., Guanche, R., 2008. Wave Interaction with Low-mound Breakwaters Using A RANS Model. Ocean Engineering. 35. Elsevier, pp. 1388-1400.

Lucy, L.B., 1977. A numerical approach to the testing of the fission hypothesis. Astron. J. 82 (12), 1013-1024.

Martins, R., 2012. Analise da interacçao entre uma onda regular e um quebra-mar vertical usando um modelo numérico Smoothed Particle Hydrodynamics (Master thesis). Universidade Nova de Lisboa, Lisbon, Portugal (in portuguese).

Monaghan, J.J., 1989. On the problem of penetration in particle methods. J. Computational Phys. 82, 1-15.

Monaghan, J.J., Kos, A., 1999. Solitary waves on a Cretan beach. J. Waterways, Ports, Coast. Ocean Eng. 125, 145-154.

Monaghan, J.J., 1992. Smoothed particle hydrodynamics. Annu. Rev. Astron. Astrophys. 30, 543-574.

Monaghan, J.J., 1994. Simulating free surface flows with SPH. J. Comput. Phys. 110, 399-406.

Neves, D.R.C.B., Didier, E., Reis, M.T., Neves, M.G., 2012. Overtopping of a porous structure using a Smoothed Particle Hydrodynamics numerical model. In: Proceedings of Coastlab12 - Fourth International Conference on the Application of Physical Modeling to Port and Coastal Protection, Ghent, Belgium.

Oñate, E., Idelsohn, S.R., Del Pin, F., Aubry, R., 2004. The particle finite element method. An overview. Int. J. Computational Methods 1 (2), 267-307.

PROVERBS, 1999. 〈http://www.tu-bs.de / i5102401.

Rogers, B.D., Dalrymple, R.A., 2008. SPH modeling of tsunami waves. In Advanced Numerical Models for Tsunami Waves and Runup, P.L.-F. Liu, H. Yeh and C. Synolakis, ed., World Scientific, 75-100, 2008.

Shao, S., 2010. Incompressible SPH flow model for wave interactions with porous media. Coast. Eng. 57, 304-316.

SPHysics code v1.4, 2009. 〈http://wiki.manchester.ac.uk/sphysics〉.

Willmott, C.J., Ackleson, S.G., Davis, R.E., Feddema, J.J., Klink, K.M., Legates, D.R., O'Donnell, J., Rowe, C.M., 1985. Statistics for the evaluation and comparison of models. J. Geophys. Res. 90 (c5), 8995-9005. 